\title{
Plausible Positive Effects of Statins in COVID-19 Patient
}

\author{
Antonio Vitiello ${ }^{2}\left[\right.$ [ Francesco Ferrara ${ }^{1}[0$
}

Received: 5 February 2021 / Accepted: 7 July 2021 / Published online: 13 July 2021

(c) The Author(s), under exclusive licence to Springer Science+Business Media, LLC, part of Springer Nature 2021

\begin{abstract}
Since the onset of the global COVID-19 pandemic, there has been much discussion about the advantages and disadvantages of ongoing chronic drug therapies in SARS-CoV-2-positive patients. These discussions include also statins treatment. The statins are among the most widely used drugs in the global population. Statins aim to lower cholesterol, which is essential for many biological processes but can lead to heart disease if levels are too high; however, also the pleiotropic effects of statins are well known. So could the anti-inflammatory or the potential antiviral effects of statins be helpful in avoiding extreme inflammation and severity in COVID-19? To date, there are conflicting opinions on the effects of statins in the course of COVID-19 infection. The aim of this article is to describe the molecular and pharmacological basis of the pleiotropic effects of statins that could be more involved in the fight against COVID-19 infection and to investigate the current epidemiological evidence in the literature on the current and important topic.
\end{abstract}

Keywords Statins $\cdot$ COVID-19 $\cdot$ Pleiotropic effects $\cdot$ SARS-COV-2

\section{Introduction}

\section{SARS-CoV-2 (COVID-19)}

In November 2019, a new coronavirus was identified as the cause of a series of severe pneumonia cases in Wuhan, China. The virus designated as Coronavirus- 2 is responsible for the severe acute respiratory syndrome SARS-CoV-2 (COVID-19). The virus has spread rapidly around the world. In March 2020, the World Health Organization proclaimed COVID-19 as a "global pandemic;" to date, there are approximately 1.7 MLN deaths and 87 MLN people infected [1]. In December 2020, the first COVID-19 vaccinations began. However, pharmacological treatments of COVID-19 infection are mostly experimental, directed at avoiding serious

Handling Editor: Dakshesh Patel.

Francesco Ferrara

francesco.ferrara@uslumbria1.it

Antonio Vitiello

antonio.vitiello2@uslumbria1.it

1 Hospital Pharmacist Manager, Pharmaceutical Department, Usl Umbria 1, A.Migliorati street, 06132 Perugia, Italy

2 Clinical Pharmacologist, Pharmaceutical Department, Usl Umbria 1, A.Migliorati street, 06132 Perugia, Italy complications of the disease [2-4]. Among the various pharmacological agents used, some antivirals indicated for other viral diseases, such as remdesivir, have shown good anti-COVID-19 efficacy [5]. SARS-CoV-2 is an RNA virus similar for about $80 \%$ of the viral genome to SARS-CoV (responsible for the 2003 outbreak) [6]. In vitro studies have shown that the virus penetrates human cells by binding to ACE- 2 protein, the angiotensin-converting enzyme 2 , which is part of the renin-angiotensin system (RAS) [7-9]. SARSCoV-2 infection in most cases has a totally asymptomatic or mildly symptomatic course. However, in a percentage of cases, the infection has a course characterized by an asymptomatic initial phase and subsequent phases characterized by a generalized inflammatory state causing tissue injury in multiple organs and a respiratory distress syndrome [10]. The generalized inflammatory state responsible for the severe lesions is caused by hyperactivation of components of the host inflammatory/immune system characterized by a massive and high release of cytokines, an event called "cytokine storm."

\section{Clinical Manifestations}

The SARS-CoV-2 virus is transmitted from human to human. The incubation period is 5 to 15 days [11]. Bilateral interstitial pneumonia appears to be the most severe 
manifestation caused by COVID-19 disease and characterized by cough, dyspnea, and respiratory failure [12]. However, the most frequent symptoms reported by the epidemiological data consist of myalgia and fatigue, elevation of body temperature, and olfactory disturbances [13]. Epidemiologic data indicate that fever is present in approximately $90 \%$ of patients hospitalized with COVID-19 [14-16]. Dermatologic reactions such as rashes and urticaria have also been reported in some cases $[17,18]$. In the most severe stages of infection, there may be involvement of the cardiovascular system and liver tissue. Data report cases of acute cardiac injury from COVID-19 [19] and thromboembolic complications, particularly pulmonary embolism [20]. Some cases report acute liver injury caused by COVID-19 [21]. SARSCoV-2 enters cells through the ACE-2 entry receptor that is expressed in several tissues, the lung, heart, and liver $[22,23]$. The multisystem inflammation that is generated is responsible for organ damage and fibrotic tissue formation in the lung, heart, and liver [24, 25].

\section{Risk Factors in COVID-19 Patients}

Epidemiologic evidence has shown that the severity of viral infection can vary significantly from person to person. Large-scale observational studies suggest that greater severity of COVID-19 is associated with demographic factors, such as older age and male sex [26]. In addition, evidence associates an increased risk of severe disease in individuals with preexisting disease. Observational studies report that hypertension is significantly higher among hospitalized COVID-19 patients than among nonhospitalized patients [27]. Metabolic disease is considered a serious COVID19 risk factor. One meta-analysis shows that COVID-19 patients with diabetes have a higher risk of severe disease than patients without diabetes [28]. Another study shows that patients with diabetes have a higher risk of COVID-19 mortality [29]. A large observational cohort study shows that obese patients have a higher risk of COVID-19 hospitalization than normal-weight patients [30]. Recent evidence shows that COPD may increase the risk of COVID-19 hospitalization [31]. Pulmonary diseases such as COPD, asthma, and cystic fibrosis can make the airways vulnerable to severe COVID-19 injury [32]. Individuals with compromised immune systems or on chronic therapy with immunosuppressive agents are at increased risk for severe COVID-19 infection [33].

Smoking individuals have increased expression of ACE2 in airway epithelial cells, predisposing an individual to SARS-CoV-2 infection [34]. A meta-analysis demonstrates that individuals who are smokers or former smokers have an increased risk of severe COVID-19 [35]. The presence of hypercholesterolemia may be a COVID-19 risk factor [36].

\section{Statins}

Statins represent a pharmacological class that has been used for many years with an undoubted therapeutic efficacy and safety profile in the management of hyperlipidemia and prevention of atherosclerotic vascular disease [37, 38]. Statins act through inhibition of hydroxymethylglutaryl-coenzyme A (HMGCoA) reductase involved in endogenous cholesterol synthesis. For several years, scientific evidence has associated the therapeutic benefits of statins with pleiotropic effects. Several experimental studies fully support the thesis that the pleiotropic effects of statins are independent of HMGCoA reductase inhibition. Among these, pleiotropic effects are stabilization of endothelial dysfunction, stabilization of atherosclerotic plaque, regulation of angiogenesis, and antifibrotic, antithrombotic, and anti-inflammatory effects [39]. The pleiotropic effects of statins represent added value in the prevention of cardiovascular disease, but can the pleiotropic effects of statins also be of clinical benefit in the chronically treated patient and COVID-19 infection? The pleiotropic effects of statins suggest potential therapeutic benefits in the patient on chronic statin therapy and with ongoing COVID-19 infection, particularly to counteract the thrombotic risk may occur in the more severe stages of SARS-CoV-2 infection.

\section{Statins Treatment's Clinical Evidence and COVID-19 Patients}

Several studies have compared the outcomes of COVID19 infections in patients chronically treated with statins compared with subjects not taking them. The results suggest that statin use potentially may reduce COVID-19 mortality. One retrospective observational study showed that statin use in hospitalized subjects with COVID-19 was associated with a lower risk of all-cause mortality and a favorable recovery profile [40]. These data also provide evidence supporting the safety of statins as monotherapy or in combination with ACEi/ARBs in patients with COVID-19. Another retrospective observational study demonstrated reduced risk of mortality from COVID-19 in patients treated with atorvastatin [41]. Much remains to be determined about the anti-COVID-19 efficacy of statin treatment, although available evidence suggests that moderate to high statin therapy may be effective [42]. Another retrospective study showed that statin use in the 30 days before hospitalization for COVID-19 was associated with a lower risk of developing severe COVID-19 and a faster recovery time among patients without severe disease [43]. Another retrospective study showed that in patients with 
hyperlipidemia, statin use was independently associated with fewer ICU admissions. This supports the current practice of continuing to prescribe statins in patients on drug treatment even if COVID-19 infection is present [44].

\section{Statins' Role in COVID-19 Infection}

Several pleiotropic effects of statins could potentially be of clinical benefit in COVID-19 patients (Fig. 1). In particular, statins are known for their pleiotropic anti-inflammatory effects, including increased expression of ACE-2 and inhibition of Toll-like receptor (TLR)-MYD88-NF-кB in vitro [45]. Evidence shows that SARS-CoV-2 interacts with Tolllike receptors on the host cell membrane, increasing MYD88 gene expression, activating NF- $\mathrm{kB}$, and triggering inflammatory pathways. Experimental models have shown that statins stabilize MYD88 levels after a proinflammatory trigger, and in a mouse model, atorvastatin significantly attenuated NF- $\mathrm{BB}$ activation. Elevated D-dimer levels and high incidence of thrombotic complications are reported in severe COVID-19 patients [46]. The role of statins in the management of venous thromboembolism has been investigated in several studies. The JUPITER study, which studied relatively healthy patients with high CRP levels, reported a significantly reduced rate of deep vein thrombosis in those who received rosuvastatin compared with placebo [47]. Several mechanisms have been proposed to explain the antithrombotic effects of statin treatment, including decreased tissue factor expression, decreased platelet aggregation, and increased thrombomodulin expression on endothelial cells [48]. It has been proposed that COVID-19 may induce a prothrombotic state, as supported by high levels of factor VIII, fibrinogen, and d-dimer [49, 50].

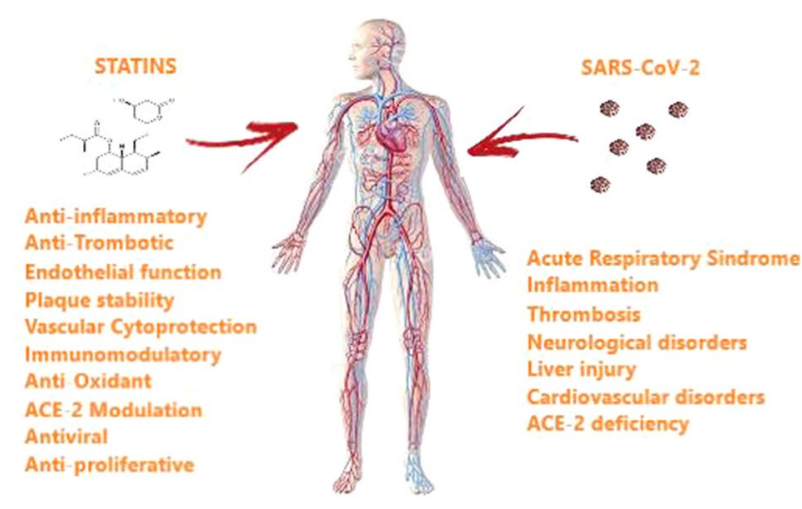

Fig. 1 In the most severe stages of COVID-19 infection, a generalized inflammatory state caused by cytokine storm can result in multi-organ damage. The pleiotropic effects associated with statin treatment, particularly the antithrombotic, anti-inflammatory, and endothelial-stabilizing effects, could be of therapeutic benefit in reducing severe COVID-19 complications
In severe COVID-19 patients, the generalized inflammatory state may cause fibrotic tissue formation. In addition, statins may have a reducing effect on cardiac and pulmonary fibrosis, hypertrophy, and pathological remodeling in response to angiotensin II (Ang II) in a Rho/ROCK-dependent manner [51-53]. Increased ROCK activity is observed in patients with hypertension, pulmonary hypertension, metabolic syndrome, dyslipidemia, acute coronary syndrome (CAD), coronary vasospasm, left ventricular hypertrophy $(\mathrm{LVH})$, and in heart failure with reduced systolic function [54-56]. Inhibition of ROCK is a candidate for mediating the pleiotropy of statins. The effect of statins on the myocardium mediated by RhoA and ROCK is of paramount importance because both lead to increased apoptosis and increased fibrosis, which could lead to the development of heart failure. In addition, growing data suggest that the respiratory failure that develops in COVID-19 infection differs from that in other types of patients in several respects [57]. Statin treatment could improve endothelial and vascular function in these patients. Features such as relatively good pulmonary compliance despite poor oxygenation, lack of pulmonary vasoconstriction, and thrombotic microangiopathy [58] suggest that vascular endothelial dysfunction plays a vital role in the pathogenesis of COVID-19 infections [59]. Endothelial dysfunction may be caused by reduced bioavailability of endothelial nitric oxide (NO). Endothelial NO is important for vasodilation, vascular smooth muscle proliferation, and endothelial leukocyte interactions. Statins increase endothelial NO production by increasing endothelial NO synthase (eNOS) [60, 61]. In the recent period, numerous in vitro and in vivo trials have associated direct anti-inflammatory effects that are not mediated by their hypocholesterolemic activity. This evidence is further supported by observations that statin therapy lowers C-reactive protein (CRP), a marker of inflammation, independently of the lipid-lowering effect [62, 63]. However, there are still many aspects to be clarified on the anti-inflammatory effect of statins. Some studies show that statins inhibit leukocyte recruitment. The activity on leukocyte migration is probably related to the reduction of chemokine, interleukin 6 (IL-6), and cytokine [64]. In addition, statin treatment can improve NO release from the endothelium and downregulate endothelial P-selectin [65]. In addition, it seems that the inhibition of the activation of the integrins is related to the reduced Geranylgeranylation of Rho [66]. By blocking the activity of Rho GTPase, the statins prevent ICAM-1 expression in endothelial cells [67]. Other evidence shows that by inhibiting the geranylgeranylation of Rho GTPase, the statins induce the expression of endothelial NO synthase (eNOS) [68, 69]. Finally, statins are associated with cytokine- and chemokine-release inhibition effects by regulating nuclear receptors, proliferator of the activated peroxisome receptor $\alpha$ (PPAR- $\alpha$ ), and PPAR- $\gamma$ [70]. Other studies 
indicate that statins could modulate the adhesion of leukocytes by interfering with the path of nuclear factor $\kappa \mathrm{B}$ (NFкB) [71-73]. Some studies have attributed direct cholesteroldependent or non-cholesterol-dependent antiviral effects to statin treatment. In fact, in this direction, many studies suggest that statins, due to their pleiotropic properties, may be beneficial for the treatment of viral infections and their complications. Some evidence has shown that statins can exert direct antiviral effects, blocking the intracellular production of cholesterol and intervening directly on the infectious cycle of viruses. Moreover, as described above, statins reduce geranylgeranyl pyrophosphate (GGP) and farnesyl pyrophosphate isoprenoids, which are necessary for the prenylation of proteins such as Rho and Ras GTPase; in particular, the latter proteins are associated to the regulation of the life cycle of viruses. This evidence has been supported by some studies that have shown that statins may have some antiviral potential against HCV. In fact, statins have been shown to have antireplicative viral activity against $\mathrm{HCV}$ when used in association with interferon [74-76]. By reducing the availability of cholesterol, statins may represent possible candidates to interfere with virus fusion and entry into host cells [77]. How much this evidence can also be associated with an anti-SARS-CoV-2 activity is to be demonstrated. A suggested mechanism could be that membrane cholesterol reduction prevents normal ACE2-spike interactions. Some evidence attributed to statins' antifibrotic effects of liver tissue and lung tissue and decreased portal hypertension. One of the antifibrotic mechanisms of statins is the reduction of proinflammatory mediators, as described above, which can induce tissue fibrosis. However, it seems that other pathways are involved. In particular, the reduction and decrease in activity of profibrotic factors such as TGF $\beta 1$ and PDGF $\beta$ are associated with statins. Moreover, by decreasing the RhoA pathway and its downstream Rho-kinase effector, collagen synthesis and liver fibrosis are reduced. Finally, a greater availability of statin-mediated $\mathrm{NO}$ causes a decrease in intrahepatic resistance and portal pressure $[78,79]$. The hyperactive inflammatory state caused by COVID-19 infection may also be responsible for fibrotic tissue formation, particularly pulmonary fibrosis that could cause severe complications. The hallmarks of the pathogenesis of pulmonary fibrosis are cell proliferation, collagen deposition, and differentiation of fibroblasts into the profibrogenic phenotype of myofibroblasts; these processes are mainly mediated by connective tissue growth factor (CTGF), an autocrine growth factor induced by TGF-b1. Some evidence suggests that statins could modify critical determinants of the profibrogenic mechanism and potentially prevent lung parenchymal remodeling associated with myofibroblast formation by inhibiting CTGF gene expression after TGF-b1 induction. Treatment with statins has been associated with antiplatelet and anticoagulant effects. A decrease in platelet activity occurs through an increase in NO. Nitric oxide (NO) is a potent inhibitor of platelet aggregation. In addition, administration of statins has been shown to decrease tissue factor (TF) expression and activity in monocytes and macrophages [80]. Thrombomodulin acts as a cofactor of thrombin in the process of protein C (APC) activation, which, by proteolytically inactivating activated factors $\mathrm{V}$ and VIII, plays an anticoagulant role [81]. The intracellular entry receptor used by SARS-CoV-2 is angiotensin-converting enzyme 2 (ACE-2), which is expressed in lung, liver, and cardiac tissue. ACE-2 is an important regulatory enzyme in the renin-angiotensin system (RAS), catalyzing the conversion of angiotensin II (AT-II) to angiotensin 1-7 (AT 1-7). AT 1-7 opposes the effects induced by AT-II, with antioxidant, anti-inflammatory, antifibrous, and vasodilator actions. It is also known that SARS-CoV-2 infection in the most severe stages causes a reduction in ACE-2. This effect may increase the likelihood of lung injury, which in some cases can be fatal. Ultimately, ACE-2 plays a dual role in COVID-19 infection, first as a protector against the damaging effects of the hyperinflammatory response and second as an entry receptor for SARS-CoV. Statins have, for years, been the therapy of first choice in the treatment of hypercholesterolemia. Studies have shown increased expression of ACE-2 after treatment with statins. Important questions arise: If statins increase ACE-2, could they be a risk factor for SARS-CoV-2 infection? Or, in the severe stages of infection, could the increase in ACE-2 be an additional protective value? To date, it is unclear how clinical outcomes in patients with COVID-19 are affected by the use of statins, alone or in combination with ACE inhibitors and ARBs. Well-structured clinical studies are needed [82, 83].

\section{Statins' Safety Profile in COVID-19 Patients}

Any drug treatment is not without possible adverse reactions [84]. Therapeutic treatments in the COVID-19 positive patient should be carefully monitored [85]. Statins are welltolerated drugs at the common doses used in the treatment of hypercholesterolemia. The patient with severe COVID-19 is a complex patient who may have organ damage, particularly to the liver and kidney with altered organ clearance and with altered statin metabolization and excretion, increased circulating concentrations, and an increased risk of inducing adverse reactions such as myotoxicity and rhabdomyolysis. Rhabdomyolysis may create additional kidney damage [86]. In addition, the elderly COVID-19 patient may have reduced hepatic and renal clearance, making the scenario even more complicated. As described, some evidence associates that a potential increase in ACE- 2 concentration induced by statin treatment could represent a COVID-19 risk factor, as the virus would find a greater amount of transmembrane receptor cell entry. In this direction, however, there is no firm 
epidemiological evidence, and to date, discontinuation of statin treatment is not recommended. In addition, most available statins are substrates for the cytochrome P450 (CYP) system, particularly the $3 \mathrm{~A}$ and $\mathrm{P}$-glycoprotein (P-gp) isoenzymes. Some antivirals used in the COVID-19-positive patient are potent inhibitors of CYP3A and P-gp, and their concomitant administration may cause a marked increase in statin concentrations with potential toxic effects [87]. Close monitoring of creatine kinase levels and liver function is recommended in these cases (Table 1).

\section{Discussion}

COVID-19 infection can result in severe pulmonary injury and a variety of extrapulmonary manifestations. The molecular pathophysiological mechanisms explaining multi-organ dysfunction are caused by the direct effects of SARS-CoV-2 infection and the indirect effects of a dysregulated immune response. The current manuscript suggests the potential benefit of pleiotropic effects of statins in COVID-19 patients. Clinical trials are ongoing to verify the possible clinical benefit of statin treatment in COVID-19 patients. The statin family is characterized by several pharmacologic agents. To date, there are no data showing differences between different statins in terms of clinical outcomes in COVID-19 disease. Presumably, the difference in pleiotropic effects among different statins could potentially diversify the clinical outcomes of COVID-19 patients depending on the statin taken. Any statin treatment may represent a powerful means of reducing COVID-19 mortality risk. However, some studies for example show that both atorvastatin and rosuvastatin cause comparable significant reductions in thromboxanedependent platelet activation and lipid peroxidation primarily related to decreased LDL-C, [88]. Other evidence indicates that rosuvastatin is superior to atorvastatin in lowering LDL-C levels [89]. These differences in biological effects among the various statins might differ clinical outcomes in COVID-19 patients. But to date, evidence in this direction is scarce. In addition, some evidence shows inconsistent data on the efficacy of statins in certain categories of patients. In particular, individuals with type 2 diabetes mellitus and COVID-19 positive. In this category of patients, routine treatment with statins is significantly associated with increased mortality in patients with T2DM hospitalized for COVID-19 [90]. In addition, the use of statins may have some contraindications; in particular, a proportion of COVID-19 patients may have liver injury and elevation of transaminases. Probably in this category of patients, routine use of statins may be additive in increasing hepatic injury. In addition, the COVID-19 patient taking antivirals may be subject to drug interactions; remdesivir and statins are both substrates of cytochrome P450 3A4 (CYP3A4), which could promote adverse effects with concomitant administration [91]. In addition, some other important questions need to be clarified: is there a dose-response relationship underlying the beneficial effect of statins in Covid-19? Is the beneficial effect different depending on the population category considered? And again, can statins be used as adjunctive therapy even in patients with Covid-19 who do not take statins on a daily basis?

\section{Conclusion and Perspectives}

Statins are drugs of undoubted therapeutic efficacy and with a good tolerability profile. Current guidelines recommend not to stop treatment in case of COVID-19 positivity. The pleiotropic effects of statins can represent an added value in patients on statin therapy for the treatment of hypercholesterolemia and COVID-19 positive. Some evidence shows additional benefits in patients treated with statins and COVID-19 positive compared to those not taking them. Further clinical trials are in progress; when we have their results, we will be able to say how useful statins may be in the treatment of COVID-19. In conclusion, we believe that statins may mitigate the effects of COVID-19 infection on the basis of pharmacological, molecular, and biochemical knowledge of pleiotropic effects, in selected patients, and in particular for the benefits associated with coagulopathy, endothelial dysfunction, and dysregulated inflammation. However, in
Table 1 Plausible positive effects of statins in COVID-19 patient

\begin{tabular}{ll}
\hline Antiviral & Antireplicative viral activity \\
& Inhibition of entry virus into host cells \\
Anti-inflammatory & Increasing the expression of ACE-2 \\
& Inhibiting Toll-like receptor (TLR)-MYD88-NF-KB \\
& Reduction of C-reactive protein (CRP) \\
Anti-thrombotic & Decreased tissue factor expression \\
& Decreased platelet aggregation \\
Anti-fibrosis & Increased thrombomodulin expression on endothelial cells \\
& Inhibition of ROCK activity \\
Reduction of vascular endothelial dysfunction & Reduction of TGF $\beta 1$ and PDGF $\beta$ \\
& Increasing endothelial NO synthase (eNOS) \\
\hline
\end{tabular}


the absence of reliable evidence, the role of statins remains uncertain and yet to be defined.

Acknowledgements The authors have nothing to say about ethical standards, ethical approval, and funding. This manuscript is not a clinical trial and does not violate ethical rules. No funding has been received for its preparation.

Author Contributions AV: Conceptualization, Writing—original draft, and Methodology. FF: Writing — review \& editing, Supervision, and Validation.

\section{Declarations}

Conflict of interest None of the authors have conflict of interest to disclose.

\section{References}

1. World health organization. (WHO). (2021). Retrieved April 2021 from, https://www.who.int/emergencies/diseases/novel-coronavirus-2019/situation-reports

2. Vitiello, A., \& Ferrara, F. (2021). Therapeutic strategies for SARS-CoV-2 acting on ACE-2. European Journal of Pharmaceutical Sciences, 156, 105579. https://doi.org/10.1016/j.ejps. 2020.105579

3. Vitiello, A., La Porta, R., \& Ferrara, F. (2020). Sacubitril, valsartan and SARS-CoV-2. BMJ Evidence-Based Medicine. https:// doi.org/10.1136/bmjebm-2020-111497

4. Vitiello, A., La Porta, R., \& Ferrara, F. (2021). Scientific hypothesis and rational pharmacological for the use of sacubitril/valsartan in cardiac damage caused by COVID-19. Medical Hypotheses, 147, 110486. https://doi.org/10.1016/j.mehy.2021.110486

5. Vitiello, A., \& Ferrara, F. (2020). Remdesivir versus ritonavir/ lopinavir in COVID-19 patients. Irish Journal of Medical Science. https://doi.org/10.1007/s11845-020-02440-y

6. Vitiello, A., \& Ferrara, F. (2021). Pharmacological agents modifying the renin angiotensin and natriuretic peptide systems in COVID-19 patients. Wiener Klinische Wochenschrift. https://doi. org/10.1007/s00508-021-01855-6

7. Vitiello, A., Ferrara, F., \& Porta, R. (2021). Remdesivir and COVID-19 infection, therapeutic benefits or unnecessary risks? Irish Journal of Medical Science. https://doi.org/10.1007/ s11845-020-02482-2

8. Li, Q., Guan, X., Wu, P., Wang, X., Zhou, L., Tong, Y., et al. (2020). Early transmission dynamics in Wuhan, China, of novel coronavirus-infected pneumonia. New England Journal of Medicine, 382(13), 1199-1207. https://doi.org/10.1056/NEJMoa2001 316

9. Ferrara, F., \& Vitiello, A. (2021). Scientific hypothesis for treatment of COVID-19's lung lesions by adjusting ACE/ACE2 imbalance. Cardiovascular Toxicology. https://doi.org/10.1007/ s12012-021-09649-y

10. Chen, N., Zhou, M., Dong, X., Qu, J., Gong, F., Han, Y., et al. (2020). Epidemiological and clinical characteristics of 99 cases of 2019 novel coronavirus pneumonia in Wuhan, China: A descriptive study. The Lancet, 395(10223), 507-513. https://doi.org/10. 1016/S0140-6736(20)30211-7

11. Guan, W. J., Ni, Z. Y., \& Hu, Y. (2020). Clinical characteristics of coronavirus disease 2019 in China. New England Journal of Medicine, 382, 1708.
12. Struyf, T., Deeks, J. J., Dinnes, J., Takwoingi, Y., Davenport, C., Leeflang, M. M., et al. (2020). Cochrane COVID-19 Diagnostic Test Accuracy Group. Signs and symptoms to determine if a patient presenting in primary care or hospital outpatient settings has COVID-19 disease. Cochrane Database of Systematic Reviews, 7(7), CD013665. https://doi.org/10.1002/14651858. CD013665

13. Chung, T. W., Sridhar, S., \& Zhang, A. J. (2020). Olfactory dysfunction in coronavirus disease 2019 patients: Observational Cohort Study and Systematic Review. Open Forum Infectious Diseases, 7, ofaa199.

14. Tong, J. Y., Wong, A., \& Zhu, D. (2020). The prevalence of olfactory and gustatory dysfunction in COVID-19 Patients: A systematic review and meta-analysis. Otolaryngology Head and Neck Surgery, 163, 3 .

15. Wang, D., Hu, B., \& Hu, C. (2020). Clinical characteristics of 138 hospitalized patients with 2019 novel coronavirus-infected pneumonia in Wuhan, China. JAMA, 323, 1061.

16. Recalcati, S. (2020). Cutaneous manifestations in COVID-19: A first perspective. The Journal of the European Academy of Dermatology and Venereology, 34, e212.

17. Arentz, M., Yim, E., \& Klaff, L. (2020). Characteristics and outcomes of 21 critically Ill patients with COVID-19 in Washington State. JAMA, 323, 1612.

18. Xie, Y., Wang, X., Yang, P., \& Zhang, S. (2020). COVID-19 complicated by acute pulmonary embolism. Radiology Cardiothoracic Imaging, 2(2), e200067. https://doi.org/10.1148/ryct.2020200067

19. Fan, Z., Chen, L., Li, J., Cheng, X., Yang, J., Tian, C., et al. (2020). Clinical features of COVID-19-related liver functional abnormality. Clinical Gastroenterology and Hepatology, 18(7), 1561-1566. https://doi.org/10.1016/j.cgh.2020.04.002

20. Chai, X., Hu, L., Zhang, Y., Han, W., Lu, Z., \& Ke, A. (2020). Specific ACE2 expression in cholangiocytes may cause liver damage after 2019-nCoV infection. BioRxiv. https://doi.org/10.1101/ 2020.02.03.931766

21. Ferrara, F. (2020). Antirheumatic in SARS-CoV-2: Benefit or risk? Italian Journal of Medicine, 14(2), 114-115. https://doi. org/10.4081/itjm.2020.1290

22. Ferrara, F., Porta, R., D’Aiuto, V., \& Vitiello, A. (2020). Remdesivir and COVID-19. Irish Journal of Medical Science. https:// doi.org/10.1007/s11845-020-02401-5

23. Vitiello, A., \& Ferrara, F. (2021). Colchicine and SARS-CoV-2: Management of the hyperinflammatory state. Respiratory Medicine, 178, 106322. https://doi.org/10.1016/j.rmed.2021.106322

24. Vitiello, A., Pelliccia, C., \& Ferrara, F. (2021). Drugs acting on the renin-angiotensin system and SARS-CoV-2. Drug Discovery Today, S1359-6446(21), 00037-00044. https://doi.org/10.1016/j. drudis.2021.01.010

25. Ferrara, F., \& Vitiello, A. (2021). Efficacy of synthetic glucocorticoids in COVID-19 endothelites. Naunyn-Schmiedeberg's Archives of Pharmacology. https://doi.org/10.1007/ s00210-021-02049-7

26. Wolff, D., Nee, S., Hickey, N. S., \& Marschollek, M. (2020). Risk factors for Covid-19 severity and fatality: A structured literature review. Infection. https://doi.org/10.1007/s15010-020-01509-1

27. Wang, D., Hu, B., Hu, C., et al. (2020). Clinical characteristics of 138 hospitalized patients With 2019 Novel Coronavirus-Infected Pneumonia in Wuhan, China. JAMA, 323(11), 1061-1069.

28. Shi, Q., Zhang, X., Jiang, F., et al. (2020). Clinical characteristics and risk factors for mortality of COVID-19 patients with diabetes in Wuhan, China: A two-center. Retrospective Study. Diabetes Care, 43(7), 1382-1391.

29. Roncon, L., Zuin, M., Rigatelli, G., \& Zuliani, G. (2020). Diabetic patients with COVID-19 infection are at higher risk of ICU admission and poor short-term outcome. Journal of Clinical Virology, 127, 104354. 
30. Fresan, U., Guevara, M., Elia, F., et al. (2020). Independent role of morbid obesity as a risk factor for COVID-19 hospitalization: A Spanish population-based cohort study. Obesity (Silver Spring), 29, 29.

31. Feng, Y., Ling, Y., Bai, T., et al. (2020). COVID-19 with different severities: A multicenter study of clinical features. American Journal of Respiratory and Critical Care Medicine, 201(11), 1380-1388.

32. Vitiello, A., La Porta, R., D’Aiuto, V., \& Ferrara, F. (2021). Pharmacological approach for the reduction of inflammatory and prothrombotic hyperactive state in COVID-19 positive patients by acting on complement cascade. Human Immunology, 82(4), 264-269. https://doi.org/10.1016/j.humimm.2021.01.007

33. Liang, W., Guan, W., Chen, R., et al. (2020). Cancer patients in SARS-CoV-2 infection: A nationwide analysis in China. The Lancet Oncology, 21(3), 335-337.

34. Radzikowska, U., Ding, M., Tan, G., et al. (2020). Distribution of ACE2, CD147, CD26, and other SARS-CoV-2 associated molecules in tissues and immune cells in health and in asthma, COPD, obesity, hypertension, and COVID-19 risk factors. Allergy, 75(11), 2829-2845.

35. Reddy, R. K., Charles, W. N., Sklavounos, A., Dutt, A., Seed, P. T., \& Khajuria, A. (2020). The effect of smoking on COVID-19 severity: A systematic review and meta-analysis. Journal of Medical Virology, 93, 1045.

36. Vitiello, A., \& Ferrara, F. (2020). Pharmacological agents to therapeutic treatment of cardiac injury caused by Covid-19. Life Sciences, 262, 118510. https://doi.org/10.1016/j.lfs.2020.118510

37. Vitiello, A., La Porta, R., \& Ferrara, F. (2020). Correlation between the use of statins and COVID-19: What do we know? BMJ Evidence-Based Medicine. https://doi.org/10.1136/ bmjebm-2020-111589

38. Law, M. R., Wald, N. J., \& Rudnicka, A. R. (2003). Quantifying effect of statins on low density lipoprotein cholesterol, ischaemic heart disease, and stroke: Systemic review and meta-analysis. $B M J, 326,1423$.

39. Takemoto, M., \& Liao, J. K. (2001). Pleiotropic effects of 3-hydroxy-3-methylglutaryl coenzyme A reductase inhibitors. Arteriosclerosis, Thrombosis, and Vascular Biology, 21, $1712-1719$.

40. Zhang, X. J., Qin, J. J., \& Cheng, X. (2020). In-hospital use of statins is associated with a reduced risk of mortality among individuals with COVID-19. Cell Metabolism, 32(2), 176-187. https://doi.org/10.1016/j.cmet.2020.06.015

41. Rodriguez-Nava, G., Trelles-Garcia, D. P., Yanez-Bello, M. A., Chung, C. W., Trelles-Garcia, V. P., \& Friedman, H. J. (2020). Atorvastatin associated with decreased hazard for death in COVID-19 patients admitted to an ICU: A retrospective cohort study. Critical Care, 24, 429.

42. Kow, C. S., \& Hasan, S. S. (2020). Meta-analysis of effect of statins in patients with COVID-19. American Journal of Cardiology, 134, 153-155. https://doi.org/10.1016/j.amjcard.2020.08.004

43. Daniels, L. B., Sitapati, A. M., Zhang, J., Zou, J., Bui, Q. M., Ren, J., Longhurst, C. A., Criqui, M. H., \& Messer, K. (2020). Relation of statin use prior to admission to severity and recovery among COVID-19 inpatients. American Journal of Cardiology, 136, 149-155. https://doi.org/10.1016/j.amjcard.2020.09.012

44. Tan, W. Y. T., Young, B. E., Lye, D. C., Chew, D. E. K., \& Dalan, R. (2020). Statin use is associated with lower disease severity in COVID-19 infection. Science and Reports, 10(1), 17458. https:// doi.org/10.1038/s41598-020-74492-0

45. Chansrichavala, P., Chantharaksri, U., Sritara, P., \& Chaiyaroj, S. C. (2009). Atorvastatin attenuates TLR4-mediated NF-kappaB activation in a MyD88-dependent pathway. Asian Pacific Journal of Allergy and Immunology, 27(1), 49-57.
46. Dolhnikoff, M., Duarte-Neto, A. N., de Almeida Monteiro, R. A., da Silva, L. F. F., de Oliveira, E. P., Saldiva, P. H. N., Mauad, T., \& Negri, E. M. (2020). Pathological evidence of pulmonary thrombotic phenomena in severe COVID-19. Journal of Thrombosis and Haemostasis, 18(6), 1517-1519. https://doi.org/10.1111/ jth.14844

47. Glynn, R. J., Danielson, E., Fonseca, F. A., Genest, J., Gotto, A. M., Jr., Kastelein, J. J., Koenig, W., Libby, P., Lorenzatti, A. J., MacFadyen, J. G., Nordestgaard, B. G., Shepherd, J., Willerson, J. T., \& Ridker, P. M. (2009). A randomized trial of rosuvastatin in the prevention of venous thromboembolism. New England Journal of Medicine, 360(18), 1851-1861. https://doi.org/10.1056/ NEJMoa0900241

48. Ferrara, F., \& Vitiello, A. (2021). The advantages of drug treatment with statins in patients with SARS-CoV-2 infection. Wiener Klinische Wochenschrift. https://doi.org/10.1007/ s00508-021-01845-8

49. Sacks, F. M., Pfeffer, M. A., Moye, L. A., Rouleau, J. L., Rutherford, J. D., Cole, T. G., et al. (1996). The effect of pravastatin on coronary events after myocardial infarction in patients with average cholesterol levels. New England Journal of Medicine, 335, 1001-1009.

50. Group TL-TIwPiIDS. (1998). Prevention of cardiovascular events and death with pravastatin in patients with coronary heart disease and a broad range of initial cholesterol levels. The New England Journal of Medicine, 339, 1349-1357.

51. Noma, K., Oyama, N., \& Liao, J. K. (2006). Physiological role of ROCKs in the cardiovascular system. American Journal of Physiology Cell Physiology, 290, C661-668.

52. Kataoka, C., Egashira, K., Inoue, S., Takemoto, M., Ni, W., Koyanagi, M., et al. (2002). Important role of Rho-kinase in the pathogenesis of cardiovascular inflammation and remodeling induced by long-term blockade of nitric oxide synthesis in rats. Hypertension, 39, 245-250.

53. Higashi, M., Shimokawa, H., Hattori, T., Hiroki, J., Mukai, Y., Morikawa, K., et al. (2003). Long-term inhibition of Rho-kinase suppresses angiotensin II-induced cardiovascular hypertrophy in rats in vivo: Effect on endothelial NAD(P)H oxidase system. Circulation Research, 93, 767-775.

54. Do, E. Z., Fukumoto, Y., \& Sugimura, K. (2013). Rho-kinase activation in patients with heart failure. Circulation Journal, 77, 2542-2550.

55. Ohnaka, K., Shimoda, S., Nawata, H., Shimokawa, H., Kaibuchi, K., Iwamoto, Y., et al. (2001). Pitavastatin enhanced BMP-2 and osteocalcin expression by inhibition of Rho-associated kinase in human osteoblasts. Biochemical and Biophysical Research Communications, 287, 337-342.

56. Ma, M. M., Li, S. Y., Wang, M., \& Guan, Y. Y. (2012). Simvastatin attenuated cerebrovascular cell proliferation in the development of hypertension through Rho/Rho-kinase pathway. Journal of Cardiovascular Pharmacology, 59, 576-582.

57. Rello, J., Storti, E., Belliato, M., \& Serrano, R. (2020). Clinical phenotypes of SARS-CoV-2: Implications for clinicians and researchers. European Respiratory Journal, 55(5), 2001028. https://doi.org/10.1183/13993003.01028-2020

58. Fogarty, H., Townsend, L., Ni Cheallaigh, C., Bergin, C., MartinLoeches, I., et al. (2020). COVID19 coagulopathy in Caucasian patients. British Journal of Haematology, 189(6), 1044-1049. https://doi.org/10.1111/bjh.16749

59. Varga, Z., Flammer, A. J., Steiger, P., Haberecker, M., Andermatt, R., Zinkernagel, A. S., et al. (2020). Endothelial cell infection and endotheliitis in COVID-19. The Lancet, 395(10234), 1417-1418. https://doi.org/10.1016/S0140-6736(20)30937-5

60. Satoh, M., Ogita, H., Takeshita, K., Mukai, Y., Kwiatkowski, D. J., \& Liao, J. K. (2006). Requirement of Rac1 in the development 
of cardiac hypertrophy. Proceedings of the National Academy of Sciences USA, 103, 7432-7437.

61. Tanaka, S., Fukumoto, Y., Nochioka, K., Minami, T., Kudo, S., Shiba, N., et al. (2013). Statins exert the pleiotropic effects through small GTP-binding protein dissociation stimulator upregulation with a resultant Rac1 degradation. Arteriosclerosis, Thrombosis, and Vascular Biology, 33, 1591-1600.

62. Ridker, P. M., Rifai, N., Clearfield, M., Downs, J. R., Weis, S. E., Miles, J. S., et al. (2001). Measurement of C-reactive protein for the targeting of statin therapy in the primary prevention of acute coronary events. New England Journal of Medicine, 344(26), 1959-1965. https://doi.org/10.1056/NEJM200106283442601

63. Taubes, G. (2002). Cardiovascular disease. Does inflammation cut to the heart of the matter? Science, 296(5566), 242-245. https:// doi.org/10.1126/science.296.5566.242

64. Diomede, L., Albani, D., Sottocorno, M., Donati, M. B., Bianchi, M., Fruscella, P., et al. (2001). In vivo anti-inflammatory effect of statins is mediated by nonsterol mevalonate products. Arteriosclerosis, Thrombosis, and Vascular Biology, 21(8), 1327-1332. https://doi.org/10.1161/hq0801.094222

65. Stalker, T. J., Lefer, A. M., \& Scalia, R. (2001). A new HMG-CoA reductase inhibitor, rosuvastatin, exerts anti-inflammatory effects on the microvascular endothelium: The role of mevalonic acid. British Journal of Pharmacology, 133(3), 406-412. https://doi. org/10.1038/sj.bjp.0704070

66. Liu, L., Moesner, P., Kovach, N. L., Bailey, R., Hamilton, A. D., Sebti, S. M., et al. (1999). Integrin-dependent leukocyte adhesion involves geranylgeranylated protein(s). Journal of Biological Chemistry, 274(47), 33334-33340. https://doi.org/10.1074/jbc. 274.47.33334

67. Takeuchi, S., Kawashima, S., Rikitake, Y., Ueyama, T., Inoue, N., Hirata, K., et al. (2000). Cerivastatin suppresses lipopolysaccharide-induced ICAM-1 expression through inhibition of Rho GTPase in BAEC. Biochemical and Biophysical Research Communications, 269(1), 97-102. https://doi.org/10.1006/bbrc.2000. 2238

68. Inoue, I., Goto, S., Mizotani, K., Awata, T., Mastunaga, T., Kawai, S., et al. (2000). Lipophilic HMG-CoA reductase inhibitor has an anti-inflammatory effect: Reduction of MRNA levels for interleukin-1beta, interleukin-6, cyclooxygenase-2, and p22phox by regulation of peroxisome proliferator-activated receptor alpha (PPARalpha) in primary endothelial cells. Life Sciences, 67(8), 863-876. https://doi.org/10.1016/s0024-3205(00)00680-9

69. Ikeda, U., \& Shimada, K. (1999). Statins and monocytes. The Lancet, 353(9169), 2070. https://doi.org/10.1016/S0140-6736(05) 77885-5

70. Grip, O., Janciauskiene, S., \& Lindgren, S. (2002). Atorvastatin activates PPAR-gamma and attenuates the inflammatory response in human monocytes. Inflammation Research, 51(2), 58-62. https://doi.org/10.1007/BF02684000

71. Zelvyte, I., Dominaitiene, R., Crisby, M., \& Janciauskiene, S. (2002). Modulation of inflammatory mediators and PPARgamma and NFkappaB expression by pravastatin in response to lipoproteins in human monocytes in vitro. Pharmacological Research, 45(2), 147-154. https://doi.org/10.1006/phrs.2001.0922

72. Laufs, U., La Fata, V., Plutzky, J., \& Liao, J. K. (1998). Upregulation of endothelial nitric oxide synthase by HMG CoA reductase inhibitors. Circulation, 97(12), 1129-1135. https://doi.org/10. 1161/01.cir.97.12.1129

73. Ortego, M., Bustos, C., Hernández-Presa, M. A., Tuñón, J., Díaz, C., Hernández, G., \& Egido, J. (1999). Atorvastatin reduces NFkappaB activation and chemokine expression in vascular smooth muscle cells and mononuclear cells. Atherosclerosis, 147(2), 253-261. https://doi.org/10.1016/s0021-9150(99)00193-8

74. Todorovska, B., Caloska-Ivanova, V., \& Dimitrova-Genadieva, M. (2019). Atorvastatin in combination with pegylated interferon and ribavirin provided high rate of sustained virological response in patients with genotype 3 hepatitis $\mathrm{C}$ virus. Open Access Macedonian Journal of Medical Sciences, 7(10), 1641-1648. https://doi.org/10.3889/oamjms.2019.459

75. Zhu, Q., Han, Q., \& Liu, Z. (2013). Potential role for statins in the treatment of chronic HCV infection. Future Virology, 8, 727-729. https://doi.org/10.2217/fvl.13.70

76. Ikeda, M., Abe, K., Yamada, M., Dansako, H., Naka, K., \& Kato, N. (2006). Different anti-HCV profiles of statins and their potential for combination therapy with interferon. Hepatology, 44, 117-125. https://doi.org/10.1002/hep.21232

77. Trebicka, J., Hennenberg, M., \& Laleman, W. (2007). Atorvastatin lowers portal pressure in cirrhotic rats byinhibition of RhoA/ Rho-kinase and activation ofendothelial nitric oxide synthase. Hepatology, 46, 242-245.

78. Marrone, G., Maeso-Diaz, R., \& Garcia-Cardena, G. (2014). KLF2 exerts antifibrotic and vasoprotective effects in cirrhotic rat livers: Behind the molecular mechanismsof statins. Gut. https://doi.org/10.1136/gutjnl-2014-308338

79. Watts, K. L., Sampson, E. M., \& Schultz, G. S. (2005). Simvastatin inhibits growth factor expression and modulates profibrogenic markers in lung fibroblasts. American Journal of Respiratory Cell and Molecular Biology, 32(290-300), 96.

80. Nadrous, H. F., Ryu, J. H., \& Douglas, W. W. (2004). Impact of angiotensin-converting enzyme inhibitors and statins on survival in idiopathic pulmonary fibrosis. Chest, 126, 438-446.

81. Meisel, S. R., Xu, X. P., Edgington, T. S., Cercek, B., Ong, J., Kaul, S., \& Shah, P. K. (2011). Dose-dependent modulation of tissue factor protein and procoagulant activity in human monocyte-derived macrophages by oxidized low density lipoprotein. Journal of Atherosclerosis and Thrombosis, 18(7), 596-603. https://doi.org/10.5551/jat.7179

82. Owens, A. P., 3rd., \& Mackman, N. (2014). The antithrombotic effects of statins. Annual Review of Medicine, 65, 433-445. https://doi.org/10.1146/annurev-med-051812-145304

83. Liao, J. K., \& Laufs, U. (2005). Pleiotropic effects of statins. Annual Review of Pharmacology and Toxicology, 45, 89-118. https://doi.org/10.1146/annurev.pharmtox.45.120403.095748

84. Lombardi, N., Crescioli, G., Bettiol, A., Marconi, E., Vitiello, A., Bonaiuti, R., et al. (2018). Characterization of serious adverse drug reactions as cause of emergency department visit in children: A 5-years active pharmacovigilance study. BMC Pharmacology and Toxicology, 19(1), 16. https://doi.org/10. 1186/s40360-018-0207-4

85. Ferrara, F., Porta, R., Santilli, P., D’Aiuto, V., \& Vitiello, A. (2020). Are multiple sclerosis therapies safe in severe acute respiratory syndrome coronavirus 2 times? Indian Journal of Pharmacology, 52(5), 441-442. https://doi.org/10.4103/ijp.IJP_ 417_20

86. Turner, R. M., \& Pirmohamed, M. (2020). Statin-related myotoxicity: A comprehensive review of pharmacokinetic, pharmacogenomics and muscle components. Journal of Clinical Medicine. https://doi.org/10.3390/jcm9010022

87. Liverpool COVID-19 drug interactions. (2020). Retrieved March 20, 2020 from, http://www.covid19-druginteractions.org/

88. Puccetti, L., Santilli, F., Pasqui, A. L., Lattanzio, S., Liani, R., Ciani, F., Ferrante, E., Ciabattoni, G., Scarpini, F., Ghezzi, A., Auteri, A., \& Davì, G. (2011). Effects of atorvastatin and rosuvastatin on thromboxane-dependent platelet activation and oxidative stress in hypercholesterolemia. Atherosclerosis, 214(1), 122-128. https://doi.org/10.1016/j.atherosclerosis.2010.10.006

89. Zhang, L., Zhang, S., Yu, Y., Jiang, H., \& Ge, J. (2020). Efficacy and safety of rosuvastatin vs. atorvastatin in lowering LDL cholesterol: A meta-analysis of trials with East Asian populations. Herz, 45(6), 594-602. https://doi.org/10.1007/ s00059-018-4767-2 
90. Cariou, B., Goronflot, T., Rimbert, A., Boullu, S., Le May, C., Moulin, P., et al. (2021). Routine use of statins and increased COVID-19 related mortality in inpatients with type 2 diabetes: Results from the CORONADO study. Diabetes \& Metabolism, 47(2), 101202. https://doi.org/10.1016/j.diabet.2020.10.001

91. Meunier, L., Meszaros, M., \& Pageaux, G. P. (2021). Letter to the Editor: Statins and COVID-19: Efficacy Still to Be Proven. Hepatology, 73(2), 875. https://doi.org/10.1002/hep.31511
Publisher's Note Springer Nature remains neutral with regard to jurisdictional claims in published maps and institutional affiliations. 